\title{
Customer Lifetime Value in B2B Markets: Theory and Practice in the Czech Republic
}

\author{
Pavel Horák ${ }^{1}$ \\ ${ }^{1}$ Czech Technical University in Prague, Department of Economics, Management and Humanities, Czech \\ Republic \\ Correspondence: Pavel Horák, Czech Technical University in Prague, Department of Economics, Management \\ and Humanities, Czech Republic. E-mail: pavel.horak@email.cz
}

Received: November 11, 2016

Accepted: January 20, 2017

Online Published: January 26, 2017

doi:10.5539/ijbm.v12n2p47

URL: http://dx.doi.org/10.5539/ijbm.v12n2p47

\begin{abstract}
We live in a time of permanent change resulting from the turbulence of business environment. Companies operate on markets with increasing competition. One of the key areas of marketing competencies thus becomes the ability of analytical work resulting from the growing volume of information. Using the differentiated CRM strategy for the correct setting of corporate strategy is not possible without systematic, targeted and contextual processing of information from various sources.

The customer has become the most valuable asset of the company. Companies are trying to build long-term relationships with their customers. Marketing managers must be able to measure, analyse and optimize the key elements affecting the development of the portfolio of customers, and identify key factors with a positive effect on growing the customer value. For small and medium-sized businesses that usually do not have big teams of specialists and thousands of customers, it is particularly true. Understanding the benefits of working with customer value and its application in creating a marketing strategy for companies operating in B2B markets is the main step that can determine the success of the company.

The aim of this article is following the basic theoretical background focused on the customer lifetime value to analyse secondary sources on this issue for B2B markets in the Czech Republic. Furthermore, to provide first findings from the ongoing research in the segment of small and medium-sized companies operating in the information technology market in the Czech Republic.
\end{abstract}

Keywords: B2B markets, Customer lifetime value, Czech market

\section{Introduction}

We live in a time whose basic certainty is a permanent change resulting from the turbulence of business environment. Companies are constantly seeking new strategies that will enable them to maintain and improve their market position. They establish new procedures for optimal company management and look for ways to use the financial resources more effectively in order to generate higher profits.

These changes affect all organizational units of the company and especially their managers. Individual specialists are still facing greater demands. An increased responsibility for company results, at the same time lays higher requirements on marketing managers regarding development of knowledge and skills.

Companies operate on markets, which are characterized by sharp competitive environment. It logically poses great challenges on marketing managers. One of the key areas of marketing competencies resulting from the growing volume of information thus becomes the ability of analytical work. The use of differentiated CRM strategy (Customer Relationship Management) for correct setting of corporate strategy is not possible without systematic, targeted and contextual processing of information from various sources and in cooperation with managers of other departments (particularly finance, sales and information technology). An active attitude of managers to implement differentiated CRM strategy for optimizing marketing expenditures could significantly affect the results of the entire company, through increased sales, by more efficient use of cross-selling and up-selling based on their thorough knowledge, and on the other hand, by cost savings. This is the result of the allocation of marketing expenses targeted at organizations with higher potential to bring value to the company.

Therefore, in a highly competitive environment, the way of survival is building long-term and mutually 
beneficial relationships with customers. For effective management, it is no longer enough to identify and take account of short-term profitability, but the focus shifts to monitoring and controlling benefits in the long-term horizon, during the entire period of the expected cooperation (Loštáková, 2009).

The customer has become the most valuable asset of the company. Marketing managers must be able to measure, analyse and optimize the key elements affecting the development of the portfolio of customers, and identify key factors with a positive effect on growing the customer value. For small and medium-sized businesses that usually do not have big teams of specialists and thousands of customers, it is particularly true. If managers fail, the impact on the company may be fatal.

The aim of this article is following the basic theoretical background focused on the Customer Lifetime Value (CLV) to analyse secondary sources on this issue for the Czech market in Business-to-Business (B2B) markets. Furthermore, to provide first findings from the ongoing research in the segment of small and medium-sized companies operating in the information technology (IT) market in the Czech Republic.

\section{Literature Review}

\subsection{Current Theoretical Basis for Determining Customer Value}

The approach to the portfolio of customers as a key company asset in literature is not new. Customer profitability issues and relationship issues of the company with its customers has been researched by many authors for a long time. Information systems supporting customer relationship management enable to collect large volumes of data, which, in connection with the accounting systems, provide invaluable information. Comprehensive knowledge of the customer or customer group has a critical impact on the financial performance of the company. It is important not only for marketing specialists, but also for the company's top management. The ability to use the systems to support the development of customer relationships and being able to assess them is fundamental for further work on customer value. There are case studies, which applied evaluation methods of customer relationship management in practice (Gupta, Lehmann, 2005). These methods, however, from my point of view, do not provide generally applicable know-how in terms of evaluation of relationships of any company.

In today's competitive world, the loss of a key customer can mean a significant loss of revenue, which could ultimately lead (especially in case of a key customer) to insolvency or, in extreme cases, even to company bankruptcy. The fight for individual customers, whether it is to keep the existing ones or acquire the new ones, thus, becomes a fight for the survival of the company.

The issue of how to assess / quantify the portfolio of customers or company's individual customers is researched by a number of renowned authors. Marketing literature includes variety of approaches trying to determine the best value of the customer.

\subsection{Customer Value Definition}

The basic philosophy of determining customer value for the company comes from the fact that customers are the primary source of the company's current and future earnings, as well as other assets.

Depending on the purpose of determining the customer value for the company, Peppers and Rogers (2004 and 2005) identify the following concepts:

- Strategic customer value (customer value is the result of applied marketing strategy that delivers increased value for that customer, and it results in a change of their value for the company)

- Current customer value (reflecting the current situation and the currently utilized strategy, benefits are estimated from the current situation)

- The potential value of a customer (includes all the benefits that a company can obtain through applying proactive strategy, the maximum obtainable profit for the period of cooperation)

Increasing attention to customer needs, identifying profitable customers in the company's portfolio and the company's dedication to create customized products along with providing full service led companies to increased interest in using two fundamental marketing models based on the evaluation of financial performance of the customer (Čermák, 2013): These are Customer Lifetime Value model and Customer Profitability Analysis model.

The primary objective of both customer-oriented models is largely identical - to find the most profitable customers and preferentially focus on them in deciding on allocation resources. However, their empirical research was largely conducted in isolation without much effort in interconnection, both in marketing literature, and in management accounting (Holm - Kumar - Rohde, 2011). 


\subsection{Customer Profitability Analysis (CPA)}

CPA analyses individual customers and their contribution to the company profit based on achieved reality and historical data. The aim of the application of this approach is to differentiate customers based on their contribution to the company. Cermak (2013) states that the CPA should help managers clearly determine which customers are profitable for the company and separate them from customers who have reduced the profitability of the company. Another objective of the CPA is to provide management with information why some customers are more profitable than others. Implementation of the CPA society has some fundamental assumptions (Van Raaij, 2005). The first is the ability to allocate costs properly. This allows using the methodology of Activity-Based Costing (ABC). The second important factor that enabled the development and application of the CPA was the deployment of information technology for the collection and analysis of customer information. Van Raaij (2005) dealt in detail with the CPA research based on ABC analysis of the obtained results at the level of an individual customer and the entire portfolio of customers. He stated that the results of the model could be applied in the process of strategic management. Holm, Kumar and Rodhe (2011) say that this model has a major disadvantage in the assumption of unchanging customer behaviour, which is in today's highly competitive environment almost unreal.

\subsection{Customer Lifetime Value (CLV)}

Customer Lifetime Value is based on the fact that the relationship between the company and its customers goes through different stages, phases of the life cycle from customer's identification, through its acquisition to the termination of the business relationship. Individual companies are examining customers' life cycles with an emphasis on revenues, respectively revenues arising from business relationships with customers, costs, respectively expenses associated with individual customers and products, the initial investment on the research and development of products sold and the cost of capital to determine the present value of cash flows (Cermak 2013). In addition, Bohari said (Bohari et al., 2011, p. 162) that CLV model from the customer perspective can be defined as "the overall value of the current and future customer base".

Peppers and Rogers (2004) define CLV as the net present value of the expected income of financial benefits from the customer. The basic premise is respecting the time value of money when the customer as well as any other asset requires an initial investment, and so it is necessary to work with the returns on this investment.

CLV reached the centre of attention as a key marketing metrics, both in academia and in business. Major global companies such as IBM, Capital One, ING and others began to use CLV modelling as a tool for measuring and managing their business (Gupta et al., 2006).

According to Gupta (Gupta et al.,2006), key factors that allowed the use of this methodology are, according to Gupta (Gupta et al.,2006):

- Increasing pressure in companies to make marketing accountable. Traditional marketing metrics as brand awareness, attitudes, or even sales and share are no longer sufficient to quantify the ROMI (Return on Marketing Investment).

- $\quad$ Financial metrics such as stock price and aggregate profit of the company or a strategy business unit do not solve the current problems of managers

- The development of information technologies has made it easy for companies to store and process huge volumes of customer transaction data.

A fundamental CLV model is based on the net present value and analyses "discounted cash flow", which was edited for the purposes of CLV by Gupta et al. (2006) as follows:

$$
C L V=\sum_{t=0}^{T} \frac{\left(p_{t}-c_{t}\right) r_{t}}{(1+i)^{t}}-A C
$$

Where

$C L V=$ customer lifetime value

$p_{t}=$ price paid by a consumer at time $t$,

$c_{t}=$ direct cost of servicing the customer at time $t$,

$r_{t}=$ probability of customer repeat buying or being "alive" at time $t$, 
$i=$ discount rate or cost of capital for the firm,

$A C=$ acquisition cost

$T=$ time horizon for estimating $\mathrm{CLV}$

There are many modifications to this fundamental formula described by renowned authors. Despite the formula seems quite simple, its usage has limits and certain risks in the presentation of the calculation result. On the Internet today, we can find different calculators to help CLV marketing specialists to get quite accurate results, unfortunately, in some cases these are calculated from the not entirely correct values and thus may lead to incorrect conclusions.

Let us look at possible risks.

\subsection{Possible Difficulties in Determining CLV in B2B Markets}

In the process of determining CLV is found, despite the optimism of some authors, a number of problems that complicate its practical applicability and distort the calculation of this value. Just the assumption that the value determined only by calculated profit with the help of the most commonly used CLV methodology, clearly determines that the most valuable customers can be a very debatable due to variety of reasons. The calculation is particularly influenced by problematic determination of individual variables (Loštáková, 2009):

- Problematic definition of income from customers and the related potential values, customer reference values

- Difficulty in cost allocation to the customer

- The issue of estimating the future duration of the relationship

- Estimate of the discount rate (for simplification, this factor is often replaced by the current interest rate)

2.5.1 General Limits of CLV Model

Čermák (2013) summarized that general limits / restrictions of CLV model are:

- The models do not solve the issue of the tax burden and the impact on cash flow, especially for international corporations that allocate their resources across countries

- Focus on customers that are „more profitable“. Reduction of customer base in favour of the most profitable customers or on the other hand, an increase in numbers of less profitable customers, are completely different strategies with their advantages and disadvantages.

- Models do not solve reasons for purchasing products from customer's point of view. Moreover, they do not solve factors for purchasing decisions, and decision-making on the re-purchase. Models should also count the costs caused by the change of supplier and their impact on a customer.

- Models do not include the risk of competition and launching of new competing products to the market.

- Risk of potential financial loss to the company, in case of the unpaid invoices or the overall customer insolvency

- Models do not work with a risk of proper allocation of costs to individual customers

With the above we can only agree and when we add the risk resulting from averaging the values used in the model of segment calculations, quality of customer data in some companies, or the ignorance of share of your own company's spending on customers in that area (share of wallet). Our precise calculations may provide not entirely valid information for decision making of the company and its future strategic direction.

\subsubsection{Problems of CLV Application in Small and Medium-Sized Companies}

CLV application in small and medium-sized companies is influenced by another major issue arising from the fact that they usually do not have analytical teams or large and numerous marketing department. The ability to effectively model / calculate CLV assumes that the marketing managers must perform their day-to-day activities and have a high-quality CRM system aggregating customer data, but they also get information based on cost control in the company. Therefore, they should have, at least, some basic knowledge of accounting and financial management of the company as well as the access to the financial data. Likewise, managers of financial departments usually do not have excess capacity to ensure the necessary changes in setting of accounting systems to achieve functional capability to allocate costs on customers. For number of smaller companies it is sometimes quite difficult to accurately monitor and assess the profitability of individual contracts, in most cases, this is considered a success. Standard accounting systems are primarily set up to monitor corporate profitability, 
or profitability of products, orders or projects. Cost allocations on the customer require not only knowledge, but especially correct setting of systems and compliance with reporting discipline.

The survival of small and medium-sized companies depends on managing daily core business. All possible additional costs associated with setting of information systems and processes, which are necessary for implementing CLV models, are usually minimized in the interest of corporate profits. This approach helps managers to meet their annual financial targets by reducing additional costs connected with implementing CLV. However, it can spoil the possibility to get quality and relevant information supporting their managerial decisions.

\section{Application of CLV Methodology in B2B Markets Focusing on the Czech Market}

\subsection{Forrester Research}

In December 2015, Pitney Bowes has published the results of the research focused on the use of CLV conducted by Forrester Consulting with following results:

Forrester compiled two studies. Quantitative research - an online survey of 120 professionals from US companies with 1000 or more employees, and qualitative interviewing of six prominent analysts and decision makers in the field. Results of the research confirmed the contribution of the CLV in the surveyed companies, especially for improving results of acquisition strategies, increased customer engagement and improved customer retention and customer loyalty. Respondents said that the CLV strategy comes from stimuli of executive level and marketing roles in the whole process are integrating and necessary for the application of outputs into practice. At the same time, they confirmed the problem of application the analysis results in real time.

Forrester defined, and in terms of research, they verified the so-called "real CLV" and its contribution to the evaluation and prioritization of customers by adding qualitative information about customers, more accurate information in real time by using data from social networks, transactional data and contextual searches. Theories linking transactional and behavioural data defined by rCLV met with interest of respondents.

\subsection{Application of CLV in the Czech Market}

In the Czech Republic, there is not much information on the practical application of CLV methodologies and neither on a prerequisite, i.e. the use of CRM. For this article, we will use the information from two previously published sources and one currently ongoing research.

The first entry is a CRM study, which was conducted in spring 2004 as a part of dissertation work (Malach, 2006). Respondents were managers of companies that provide consulting services in CRM and related technologies. Respondents of the study, experts on CRM in the Czech Republic, consider variable value of customer relationships as the key to corporate management. Only $32 \%$ their clients, however, tried to launch a process to assess the relationship with their customers. Most companies implementing CRM technology did not have, and still have no practically useful tools for evaluating customer relationships. Results of the study show that only a third of managers of companies implementing CRM technology monitor the real positive financial benefits of these projects. This problem appears to the author of this project as fundamental, especially at medium and larger companies, on which the work was focused.

The second source for describing the situation in the Czech market is a detailed analysis of the detailed research that can be used to compare the findings of the above study by Forrester. It was published in the textbook Differentiated Customer Relationship Management (Loštáková, 2009). In 2006, University of Pardubice conducted qualitative research aimed at using marketing strategies of companies operating in B2B markets in the Czech Republic (Loštáková 2009). Part of this research were also questions of whether and how companies use principles of customer value in marketing strategies. This qualitative research used the method of individual in-depth interviews based on structured scenarios carried out in 26 companies operating in B2B markets, particularly in the chemical, engineering, electrical and plastics manufacturing industry. Respondents were directors and strategy business unit managers, marketing, sales and customer support managers.

The results of this unique research, although they confirmed that managers are aware of the benefits of using the customer value, for its part they consider both current and future benefits, but in the context of theoretical models mentioned in the previous section, they do not work with it. Loštáková (2009, p. 134) states that in contrast with how the managers speak of the importance of customer value and express how they perceive it, in real practice, they does not attempt to quantify it. The emphasis during the segmentation strategy for the use of differentiated CRM strategy is imposed on current benefits from customers, when the customers are classified according to traditional criteria, i.e. achieved revenue. Turnover volumes are important to them in terms of the 
proportion of customers to utilize production capacity and their contribution to the overall profit. The fact that information about customer income belongs to the basic records of the company and it is a part of accounting, allows this approach to be used relatively easily in a dynamic market environment. Although managers report that they differentiate an individual offer according to two basic criteria, (they list common profit and lifetime value of each customer to the company and at the same time the length of the relationship with customers), the fact remains, that the classic modelling of customer value using a CLV methodology as defined by Gupta (Gupta et al., 2006) and Kumar (Kumar V., 2007) is not often used in the real practice of Czech companies which were surveyed for this purpose. In retrospect, we can say that this follows the situation when in the 1990s; the first CRM systems and strategies for their application entered the Czech market. However, the actual practical use of CRM systems, in accordance with scientific procedures was not common for many companies even in 2005 .

There are many reasons to this. Loštáková described, that one of the main problems is the situation, when companies do not pursue costs on customers within their daily practice. In most companies, costs allocate to the product (product, project, and contract) and not to the customer. For assessing customer profitability, companies commonly use the following metrics: revenue per customer, the type of margin (based on contributions of all products purchased by a customer) and profit per customer (calculated as the sum of income from products purchased by customer).

Research (Loštáková, 2009) indicated that setting CLV meets in practice number of problems, both on the revenue side (difficulty in defining revenue, particularly of the non-financial nature, for example based on the reference value of customer or income based on information), and especially on the cost side (the problem is not only their factual observation, but their basic allocation - marketing, sales, support service and eventually selected overheads). The introduction of monitoring CLV is not possible without effective use of systems supporting data collection and analysis tools to ensure their conversion to information, and even special customization and improvement of the existing accounting system.

First findings from the ongoing research of small and medium-sized businesses (SMB) operating in the B2B information technology (IT) market, which is carried out in the frame of the dissertation, indicate that the situation in companies over the past ten years has not changed significantly. This qualitative research is conducted by using the method of individual in-depth interviews based on structured interviews scenarios. Preliminary results are, in most cases, identical to findings that Loštáková recognized in 2006. Although companies progressed in using CRM to support decision-making and marketing strategies, their work on customer value is always based on three fundamental attributes:

- Currently and historically achieved customer revenues,

- Profitability of completed and ongoing projects with existing customers

- Incomes from long-term contracts, signed service contracts and technical support for products already delivered to the customer

Evaluation of new potential customers is based on the assessment of interest / sales of existing products and upcoming projects, forecast in the maximum term of two years.

Compared with the findings of Forrester, or the econometric research focused on the use of CLV for the analysis of real data on the sample of 35000 customers of IBM (Kumar, Venkatesan, Bohlin, \& Beckman, 2008), it is evident that the reality of the Czech market does not seem very progressive. We should be aware of a few key differences. Researches of reputable agencies and authors often focus on the biggest players in the market, for which the testing and use of modern methods is prestigious (even the mentioned IBM had objection to the actual use of the model due to the exclusion of the impact of competition and macroeconomic changes). These companies have both financial and human resources, which can be allocated to testing, research and practical application of new methods and procedures without any negative impact on their daily business. At the same time, most large companies have shares traded on the stock exchange, and that is a good signal for investors that company managers are trying to optimize process efficiency, reduce costs and maximize profits. However, within such researches, it is necessary to take into account the subject of the company's business and target markets where the company's products apply.

Moreover, we often ignore the influence of key performance indicators (KPI) of executive managers, who, in many cases, are set on the horizon of 1 year. This has an impact on their priorities, focusing on solving current problems and maximum extraction of customers, with regard to optimizing costs and to achieve defined goal based on which they are evaluated. From their perspective, the question arises whether it would be better to focus efforts on maximum extraction of profitable clients from their own portfolio than to concentrate most 
resources on the acquisition of new clients. Winning customers over competition is very demanding and expensive - except, we have a unique product that competition does not offer and it can increase customer's competitiveness in their own business. Targets of companies are repeated purchases (cross-selling and up-selling) by corporate customers, which are significantly affected by cognition of the internal decision-making processes of the customer, competitor's activity, the success of business in their own field (development of their industry and their competitors) and this is not included in many of mathematical models.

In my opinion, the specifics of individual segments of business, the size of a company, and the availability of large volumes of customer data, significantly affect the possibilities of using the existing CLV calculation models. Loštáková (2009), who focused on industrial businesses and major companies operating in the Czech market, which by their size do not entirely commensurate with multinational corporations like IBM, or the largest companies in the US market, which were surveyed within Forrester research, also confirms this. Moreover, if you look even lower, to medium-size and small businesses, the real use of CLV according to these models is even more complicated.

\section{Marketing Managers in Small and Medium-Sized Companies Are Seeking Simplifications-Example from Practice}

The consequence of the changes taking place in the market brings the need for changes in the management of companies. This has a major impact on work of marketing managers. As we mentioned above, the effective evaluation of results of marketing activities is the necessary analytical knowledge and access to relevant data. Managers of should to segment a portfolio of customers, and they are not able to identify and allocate the costs on customers, they also have a problem with the predictions in a long-term horizon. Due to all this, they look for additional metrics that can help them in an efficient allocation of marketing resources. The basis for them is the segment classification and evaluation of key attributes that differentiate customers from different industries. This task is hard to implement, if the company does not have an operational CRM system in which the data is integrated. If a sales person enters information into CRM system, which can supplement transactional data, they help them to process customer profile. The manager obtains primary information about customer purchasing behaviour, the structure of their expenditure within our product portfolio, and the decision-making process. The obtained data cost nothing from the perspective of external costs. Based on discussions with customers, sales people can gradually decipher the future needs and realistic customer skills at all levels, including the products and services supplied by competitors. Such approach places great demands on cooperation between sales and marketing departments, for a reporting obligation. Employees should be aware that even the unrealized business case could bring important information that can be valued in the future. The ability to get information about the internal affairs and processes of the customers' companies is very important for developing new business, and it very much depends on the relationship and mutual trust with the customer.

While defining CLV and its contribution to the company, marketing managers use the help of various simplifications and procedures that replace more exact approach used in CLV models. Logically, transaction data is the starting point. How can they estimate the total potential of the customer? Let's set a model example of how to estimate the potential of customer, which helps us to estimate our share on their expenses.

One of the interviewed companies uses an interesting approach, which helps them to determine their share of customer spending (share of wallet):

A firm supplies their products to major companies within different industries, each of them has their own specific demands on IT use and their expenses on IT are similar on average of the segment. There are sector studies that analyse spendings on IT - e.g. for the financial sector (banks, insurance companies ...) utilities sector (power, gas, water), telecommunications, machinery industry. These analytical studies say that these expenses are sometimes expressed as a percentage of the company's turnover, and they are further divided into the detailed structures for operational and investment costs. On the Czech market, it is possible to analyse government spendings through available data on public procurement (their volume, result). Such obtained information allows marketing specialists to calculate the company's share on total expenditure of customers in their product field and identify opportunities for future development of the relationship. Following that continues pre-sale communication that aims at verification of information. At the same time, it offers customers optimization of using IT resources with the objective to reduce costs. This information helps the company during optimization of the offer for a particular customer.

\section{Conclusion}

Working with customer value is one of the key roles of marketing managers for the future. In addition, the evaluation methodology and calculation methods will probably be different for different business segments. It 
will also depend on the phase of business cycle of products.

In some fields of business in B2B markets, there have been possibilities for the use of some models of CLV for many years, and the customer value is already being used, even though with a different internal designation. Typically, these are the financial sector and telecom operators. Both these segments have high-quality transaction data and other sources of information from which companies can very well predict customer's behaviour and analyse the phase of the life cycle. In these segments, we can expect use of patterns to determine the value of customers at a higher level also within the Czech Republic. Using CLV methodology in other industries in the Czech Republic, in my opinion, is going to develop more slowly.

In this case, however, the research itself is complicated. Within the questionnaire survey, it is quite difficult to verify the mutual understanding of respondents, what is really meant by the term of customer value. Following that, the answers of respondents can lead the research analyst to somehow not quite correct conclusions. On the other hand, structured interviews can reveal the problem of corporate reality. For example, how the company practice allocates acquisition costs, how they operate with maintenance costs and other company processes that can influence the calculation of customer value. However, this research approach is much more demanding.

At the same time, the dynamics of the IT market requires continuous verifications of calculated results of customer value due to the ever-growing activities of competition and development of new technologies.

In any case, there are still many unanswered questions, and in future research; undoubtedly, many analysts will focus specifically on some of the problematic attributes negatively affecting results in the calculation of CLV by the current standard models. Consequently, it is expected that these models will be supplemented by incorporating the methodology of correct metric calculation and last, but not least, there will be the inclusion of non-financial factors of profitability which also significantly influence the customer value. Especially, the value of a customer reference plays quite significant role in the Czech market.

\section{References}

Berger, P. D., \& Nasr, N. I. (1998). Customer Lifetime value: Marketing Models and Applications. Journal of Interactive Marketing, 1 , 17-30. https://doi.org/10.1002/(SICI)1520-6653(199824)12:1<17::AID-DIR3>3.0.CO;2-K

Bohari, A. M. et al. (2011). Customer Lifetime Value Model in Perspective of Firm and Customer: Practical Issues and Limitation on Prospecting Profitable Customers of Hypermarket Business. International Journal of Business and Management, 8, 161-169. https://doi.org/10.5539/ijbm.v6n8p161

Čermák, P. (2013). Analýza modelu hodnoty životního cyklu zákazníků. Český finančni a účetní časopis, 4, 84-95. https://doi.org/10.18267/j.cfuc. 355

Doyle, P. (2000). Value-based marketing. Journal of Strategic Marketing, 4, 299-311. https://doi.org/10.1080/096525400446203

Forrester Consulting thought leadership paper commissioned by Pitney Bowes. (2015). Making Customer Lifetime Value Real. Retrieved from http://www.pitneybowes.com/us/making-lifetime-value-real.html

Gupta S., \& Lehmann, D. R. (2005). Managing Customers as Investments (The Strategic Value of Customers in the Long Run). Wharton School Publishing.

Gupta, S. et al. (2006). Modelling Customer Lifetime Value. Journal of Service Research, 2, 139-155. https://doi.org/10.1177/1094670506293810

Gupta, S. Lehmann, D. R., \& Stuart, J. A. (2004). Valuing Customers'. Journal of Marketing Research, 1, 7-18. https://doi.org/10.1509/jmkr.41.1.7.25084

Holm, M., Kumar, V., \& Rohde, C. (2011). Measuring Customer Profitability in Complex Environments: An Interdisciplinary Contingency Framework. Academy of Marketing Science, Journal of the Academy of Marketing Science, 3, 387-401.

Jain, D., \& Singh, S. S. (2002). Customer Lifetime Value Research in Marketing. A Review and Future Directions. Journal of Interactive Marketing, 2, 34-46. https://doi.org/10.1002/dir.10032

Kaplan, R. S., \& Narayanan, V. G. (2001). Measuring and Managing Customer Profitability. Journal of Cost Management, 5, 5-15.

Kumar, V. (2007). Customer Lifetime Value - The Path to Profitability. Foundation and Trends in Marketing, 1, 1-96. https://doi.org/10.1561/1700000004 
Kumar, V., Venkatesan, R., Bohling, T., \& Beckmann, D. (2008). The Power of CLV: Managing Customer Lifetime Value at IBM. Marketing Science, 4, 585-599. https://doi.org/10.1287/mksc.1070.0319

Loštáková H. (2009). Diferencované ř́zení vztahů se zákazniky. Grada Publishing.

Malach J. (2006). Návrh metody hodnocení vztahů se zákazniky (Doctoral dissertation, University of Economics, Prague). Retrieved from https://www.vse.cz/vskp/876_navrh_metody_hodnoceni_vztahu_se_zakazniky3864_malach.pdf

Peppers D., \& Rogers, M. (2005). Return on Customer (Creating Maximum Value from Your Scarcest Resource). London: Marshall Cavendish and Cyan Com.

Peppers, D., \& Rogers, M. (2004). Managing Customer Relationship. New Jersey: John Wiley\&Sons.

Pfeifer, P. E., Haskins, M. E., \& Conroy, R. M. (2005). Customer Life Time Value, Customer Profitability, and the Treatment of Acquisition Spending. Journal of Managerial Issues, 1, 11-25.

Reinartz, W. J., \& Kumar, V. (2003). The Impact of Customer Relationship Characteristics on Profitable Liftetime Duration. Journal of Marketing, 1, 63-79.

Thomas, J. (2001). A Methodology for Linking Customer Acquisition to Customer Retention. Journal of Marketing Research, 2, 262-268. https://doi.org/10.1509/jmkr.38.2.262.18848

Van Raaij, E. M. (2005). The Strategic Value of Customer Profitability Analysis. Marketing Intelligence \& Planning, 4, 372-381. https://doi.org/10.1108/02634500510603474

\section{Copyrights}

Copyright for this article is retained by the author(s), with first publication rights granted to the journal.

This is an open-access article distributed under the terms and conditions of the Creative Commons Attribution license (http://creativecommons.org/licenses/by/4.0/). 